\title{
A citação em textos científicos: uma análise semio- historiográfica do argumento de influência
}

DOI: http://dx.doi.org/10.21165/el.v50i1.2945

\author{
Patricia Veronica Moreira' \\ Flavia Karla Ribeiro Santos ${ }^{2}$ \\ Jean Cristtus Portela ${ }^{3}$
}

\section{Resumo}

Neste trabalho visamos à formulação de uma proposta metodológica para a análise de citação em textos científicos de Semiótica, de uma perspectiva semio-historiográfica. Em Historiografia Linguística $(\mathrm{HL})$, o reconhecimento público oferece as primeiras bases de uma historiografia conceitual sobre a noção de influência. Cremos, porém, que ele pode ser dificultado pela "citação assimilada" e a Semiótica contribui para a confirmação dessa hipótese com estudos sobre intertextualidade, interdiscursividade e operações de triagem e mistura. Ao analisarmos a influência intelectual nas práticas científicas citacionais dos semioticistas, observamos que as citações direta e indireta constituem prova textual ao reconhecimento público e as operações de mistura de grau máximo (fusão) transformam discursos referenciais em citações assimiladas, dificultando o reconhecimento público de um autor em uma pesquisa historiográfica.

Palavras-chave: citação; influência; historiografia linguística; mestiçagem; semiótica discursiva.

\footnotetext{
1 Universidade Estadual Paulista "Júlio de Mesquita Filho" (UNESP), Araraquara, São Paulo, Brasil; moreira.patricia.letras@gmail.com; https://orcid.org/0000-0002-4011-9909..

2 Universidade Estadual Paulista "Júlio de Mesquita Filho" (UNESP), Araraquara, São Paulo, Brasil; flaviakarlar@hotmail.com; http://orcid.org/0000-0002-9393-2346.

3 Universidade Estadual Paulista "Júlio de Mesquita Filho" (UNESP), Araraquara, São Paulo, Brasil; jeanportela@gmail.com; http://orcid.org/0000-0002-4070-1149.
} 


\title{
The citation in scientific texts: a semio-historiographic analysis of the argument of influence
}

\begin{abstract}
In this work, we aim to formulate a methodological proposal for the analysis of citation in scientific texts of Semiotics, from a semio-historiographical perspective. In Linguistic Historiographic (LH), public acknowledgment offers the initial bases for conceptual historiography on the notion of influence. We believe, however, that it can be hindered by the "assimilated citation", and Semiotics contributes to the confirmation of this hypothesis with studies on intertextuality, interdiscursivity, and sorting and blending operations. By analyzing the intellectual influence on the semioticians' scientific citational practices, we observe that the direct and indirect citations constitute textual evidence for public acknowledgment and the maximum degree blending (merging) operations transform referential discourses into assimilated citations, complicating public acknowledgment of an author in historiographical research.
\end{abstract}

Keywords: citation; influence; linguistic historiography; miscegenation; semiotics of discourse.

\section{Introdução: quando HL e Semiótica Discursiva se imbricam}

A Semiótica Discursiva e a Historiografia Linguística (doravante HL) são duas disciplinas científicas jovens, erigidas a partir dos anos 1960. A primeira, grosso modo, diz respeito à significação e aos modos como o sentido é construído e apreendido nos mais variados textos e discursos (GREIMAS; COURTÉS, 2008). A segunda busca a descrição e a explicação do conhecimento linguístico, enquanto produto, e o seu desenvolvimento, em um determinado contexto ao longo do tempo (ALTMAN, 2009), ou seja, é uma atividade de compreensão e de escrita da história baseada em princípios específicos (KOERNER, 2014).

Da nossa perspectiva, as duas teorias podem se beneficiar mutuamente, pois a Semiótica Discursiva, por ser uma disciplina de metalinguagem característica e de forte dispersão teórica (práticas semióticas, sociossemiótica, semiótica tensiva, subjetal, visual, entre outras), ao se debruçar sobre sua história de maneira consciente e baseada na epistemologia da $\mathrm{HL}$, forneceria aos seus estudiosos uma ampla visão da emergência e do estabelecimento de seus conceitos. $\mathrm{A} \mathrm{HL}$, de sua parte, seja no âmbito dos princípios de imanência, de contextualização ou de adequação, poderia se apoiar na metodologia da Semiótica, que trata justamente do texto, para compreender o seu objeto histórico enquanto discurso. 
Jean Cristtus Portela (2018), no artigo "História das ideias semióticas: entre cronistas e inovadores", já vislumbra, no fazer do semioticista, a implicação, de alguma forma, do fazer do historiógrafo, pois aquele, ao selecionar suas fontes e organizá-las, estaria se apropriando da própria história da teoria:

[...] vemos que a atividade dos historiógrafos um pouco distraídos que nós somos não compreende apenas "projetos intencionais", projetos explícita e conscientemente historiográficos. Isso nos autoriza a supor que o pensamento historiográfico é próprio ao pensamento científico, especialmente nas ciências humanas, em que a noção de progresso resta sempre por construir e por defender. (PORTELA, 2018, p. 140).

Dito isso, Portela (2018) demonstra em seu texto os diferentes modos de os semioticistas se apropriarem da historiografia, estabelecendo uma tipologia de cronistas e inovadores. Da primeira filiação, Portela destaca as seguintes obras: Sémiotique: l'École de Paris (Coquet et al.) e História concisa da semiótica (Hénault). Da segunda, temos partes de Razão e poética do sentido (Zilberberg) e do preâmbulo na obra Atelier de sémiotique visuelle (Hénault) (PORTELA, 2018). O pesquisador conclui enfatizando que os semioticistas deveriam historiografar a semiótica semiotizando a historiografia, constituindo uma meta-historiografia de ordem semiótica, uma vez que a teoria se ocupa do sentido, do fazer sentido, tendo, portanto, muito a contribuir com e para a HL.

Lançados esses primeiros imbricamentos entre as disciplinas, voltamos nossa atenção para um aspecto relevante na condução de um estudo historiográfico conceitual que constrói seu objeto a partir da emergência de um conceito e segue seus desdobramentos mais atuais, por exemplo, quando pensamos na questão da percepção na Semiótica Discursiva oriunda dos primeiros trabalhos de Greimas (1966), em Semântica estrutural, que se destaca pela influência explícita (reconhecimento público) da fenomenologia merleau-pontiana e permanece em seus demais trabalhos, ganhando intensidade em De l'imperfection (1987), tendo continuação nos trabalhos de outros semioticistas que pertenciam ao mesmo grupo de especialidades, o da Escola de Paris: Fontanille, Landowski, Zilberberg, entre outros (pós-greimasianos) (MOREIRA, 2019).

A questão da influência é um problema que remonta às primeiras preocupações na $H \mathrm{~L}$, justamente porque está diretamente relacionada às conhecidas revoluções científicas nas ciências (KUHN, 1997), quando estamos, de fato, diante de mudanças de paradigmas e/ou de certas rupturas e/ou elementos que nos indicam continuidades teóricometodológicas. Segundo Koerner (1996, p. 62), encontramos frequentemente na história linguística mais casos de evolução/continuidade do que de revolução/descontinuidade das ideias, marcados por "movimentos de pêndulos, às vezes causados pelos afluxos extralinguísticos, tais como, avanços em tecnologias, mas também acontecimentos sócio-políticos". 
Sendo a HL uma disciplina consciente de sua metodologia e de seus parâmetros, o argumento de influência também deve ser considerado em seu escopo por meio de alguns procedimentos (KOERNER, 2014; BATISTA, 2013) que guiem o trabalho do historiógrafo para não usar imprecisamente a influência ao construir a historiografia de seus objetos. O reconhecimento público, nesse sentido, é um dos parâmetros para se atribuir influência de determinadas correntes teóricas ou autores. Trata-se de um elemento que se faz presente nos diversos modos de se fazer ciência, uma vez que a construção científica decorre também do aspecto cumulativo do saber, isto é, quando pontuamos um saber temporalmente, instauramos o horizonte retrospectivo (AUROUX, 2008) mediante uma rede de citações (influências). Essas citações colocam em evidência uma arquitetura própria (ROMANCINI, 2010) que vai do espaço micro (a própria citação) ao espaço macro (sistema científico).

Sobre a pertinência da metodologia semiótica ao se refletir sobre a influência, Zilberberg (2004, p. 71), ocupando-se dos regimes tensivos da triagem e da mistura, desenvolve um estudo sobre a mestiçagem, fenômeno definido como "uma prática semiótica figural" que possibilita identificar o processo de mistura em um dado domínio e, mais do que isso, o tipo de mistura que decorre desse processo. Sendo assim, o uso da citação na escrita científica, prática acadêmico-científica que engloba outras práticas - leitura, pesquisa, levantamento e a seleção de dados, etc. - , pode ser observado do ponto de vista da mistura/mestiçagem, já que essa prática englobante opera transformações por misturas recursivas (introdução de argumento de influência, em termos historiográficos, ou de discurso referencial, da perspectiva semiótica) que se desdobram em uma (re) contextualização de um dado saber (LIMA, 2019).

Levando em consideração esses aspectos, exploramos, nas seções seguintes, como o argumento de influência aparece em publicações sobre Semiótica Discursiva, contribuindo, assim, para a identificação, nesses textos, dos graus de reconhecimento das influências, haja vista a presença mais ou menos explícita de evidências textuais de que um texto faz referência a outro texto. Dessa forma, podemos demonstrar como a citação pode se beneficiar de uma abordagem semio-historiográfica (SANTOS, 2020)4.

\section{Sobre a citação}

Refletir sobre o reconhecimento público por meio das citações enquanto referenciação explícita nos levou às indagações mais diversas, concernentes, sobretudo às escolhas citacionais que fazemos em nossos trabalhos e às motivações que nos conduzem a introduzir ou excluir determinados autores e obras. Ademais, questionamos também se

40 termo "semio-historiografia" surge na investigação de doutorado de Santos (2020), ao estudar a figuratividade na Semiótica, amalgamando elementos metodológicos da Semiótica e da HL, na esteira dos trabalhos de Portela (2018) e de Moreira (2019). 
haveria alguma tipologia que evidenciasse a função da citação no texto em si. Para tanto, iniciamos nosso percurso em busca dessas respostas que objetivam potencializar os estudos de reivindicação de influência, expondo, assim, os sistemas científicos a que os autores se remetem e que inserem em seus trabalhos. Ao mesmo tempo, seria possível demonstrar as fontes dos autores estudados, aquelas comuns entre eles e/ou aos grupos de especialidades, correlacionando-as ao zeitgeist ou clima de opinião em que determinado conhecimento foi produzido.

Primeiramente, retomamos no trabalho de Aksnes, Langfeldt e Wouters (2019) o papel das citações em textos científicos, cuja discussão aponta que são muitas as razões que culminam na citação de um trabalho científico, destacando-se as seguintes:

[...] oferecer leitura de base, identificar metodologia, prestar homenagem aos pioneiros, identificar publicação original ou outro trabalho que descreva um conceito eponímico, identificar publicações originais em que uma ideia ou um conceito foi discutido, dando crédito a trabalhos relacionados, criticar trabalhos anteriores, corrigir um trabalho, substanciando créditos, alertas para um trabalho futuro, prover indicações para trabalhos pouco disseminados, autenticar dados e categorias de fato - constantes físicas e etc. - refutar trabalhos de outros, e disputar prioridade de créditos. (AKSNES; LANGFELDT; WOUTERS; 2019, p. 4, tradução nossa) $)^{5}$.

Percebe-se que, segundo esses autores, as citações podem decorrer de diferentes situações de escrita científica. Por isso, elas são escolhas singulares e voltadas para modalidades de escrita acadêmica diversas, cada qual seguindo os próprios protocolos, somando-se à escolha particular do enunciador por um ou outro discurso de referência, a depender da sua intencionalidade e de seu conhecimento de mundo.

Concernente à intencionalidade do enunciador, na medida em que todo discurso visa fazer o enunciatário crer na enunciação enunciada, para que isso aconteça, a citação pode ter pelo menos cinco funções no texto, sempre relacionadas com um tipo de trabalho citado. Assim, tem função negativa o trabalho refutado; função superficial, o trabalho apenas observado; função comparada, o trabalho revisado; função utilizada, o trabalho aplicado e função substanciada, a citação de um trabalho apoiado, conforme Small (1982 apud AKSNES; LANGFELDT; WOUTERS, 2019).

5 No original: "[...] providing background reading, identifying methodology, paying homage to pioneers, identifying original publication or other work describing an eponymic concept, identifying original publications in which an idea or concept was discussed, giving credit for related work, criticizing previous work, correcting a work, substantiating claims, alerts to a forthcoming work, providing leads to poorly disseminated work, authenticating data and classes of fact-physical constants and so on -disclaiming works of others, and disputing priority claims". 
Para tratar do par citado-citante, aspecto fundamental da prática de citação, Romancini (2010) destaca o papel da recursividade no processo citacional - citação de um texto em outro, ou seja, que pode se referir também a outro(s) texto(s). O pesquisador acrescenta que esse processo nos permite identificar a existência de uma rede que disponibiliza na arquitetura citacional o nível micro da ciência e o macro, isto é, o sistema científico em que a citação está inserida (ROMANCINI, 2019), indicando como o uso das citações nos textos coloca em movimento o horizonte retrospectivo do saber, enquanto aspecto cumulativo. Consequentemente, a recursividade inerente às citações demonstra, eficientemente, "[...] o caráter coletivo das realizações científicas em cada momento no tempo" (LEYDESDORFF, 1998, s/p, tradução nossa) ${ }^{6}$.

As possíveis funções da recursividade das citações não esgotam a questão da tipologia citacional, que pode ser desenvolvida a partir da relação entre a cultura da citação e a manutenção/refutação de valores científicos, contribuição cara ao trabalho historiográfico, como veremos a seguir.

\section{Influência e regimes de triagens e misturas}

$\mathrm{Em} \mathrm{HL}$, a rede de referências (citações) em textos de um dado autor constitui um recurso de identificação das influências de trabalhos já conhecidos dos enunciatários dos textosfontes examinados em uma pesquisa historiográfica, visto que estudos e reflexões teóricocientíficos podem agir de maneira mais ou menos direta sobre as transformações nas formas de pensar um conceito, uma ideia, uma teoria. As citações propiciam, portanto, à análise historiográfica, "[...] observa[r] diferentes tipos de diálogos estabelecidos no processo histórico, tendo em vista características da própria natureza social e cultural de cada época", compondo, junto ao clima de opinião, o argumento de influência de um autor/pesquisador (BATISTA, 2013, p. 93-94).

Segundo Koerner (2014), existem três tipos de influência: i) prova textual, ou seja, o estabelecimento de paralelos textuais entre dada teoria/ideia/conceito e suas supostas fontes; ii) reconhecimento público, que são as referências diretas, por parte de um autor, a obras de outros autores; e iii) background do autor, isto é, dados sobre sua tradição familiar, escolaridade, seus interesses de estudos, provas que estabelecem conexões com empréstimos, integração, assimilação de ideias, conceitos ou teorias. Como a investigação da influência exige a adoção de critérios, as propostas de Fontanille e Zilberberg (2001) e de Zilberberg $(2000,2004)$ se somam ao estudo da influência para comprovarmos como ocorre, no texto, a assimilação de dois enunciados.

Ao tratarem da construção de valores no discurso, Fontanille e Zilberberg (2001) apontam para dois regimes, um fundado nos valores de absoluto, o da exclusão (triagem), cuja

6 No original: "[...] the collective character of scientific achievements at each moment in time". 
tonicidade máxima repousa na unidade, e outro fundado nos valores de universo, o da participação (mistura), voltada para a extensão, em direção à universalidade. Em outras palavras, o operador da triagem mobiliza a concentração dos valores enquanto o operador da mistura mobiliza a sua expansão. Na condição de "variedade" da mistura no espaço tensivo, a mestiçagem pode ser definida "[...] pela fraqueza de sua valência intensiva e [...] pela elevação de sua valência extensiva". Assim, ao contrário da concentração operada pelo regime de triagem, na mistura, a recursividade (recorrência de operações de mistura) "[...] faz com que ocorra uma diluição do quantum de afeto no eixo da intensidade e uma difusão no eixo da extensidade" (ZILBERBERG, 2004, p. 74-75), que pode ser assim representada:

Gráfico 1. Correlação entre triagem e mistura

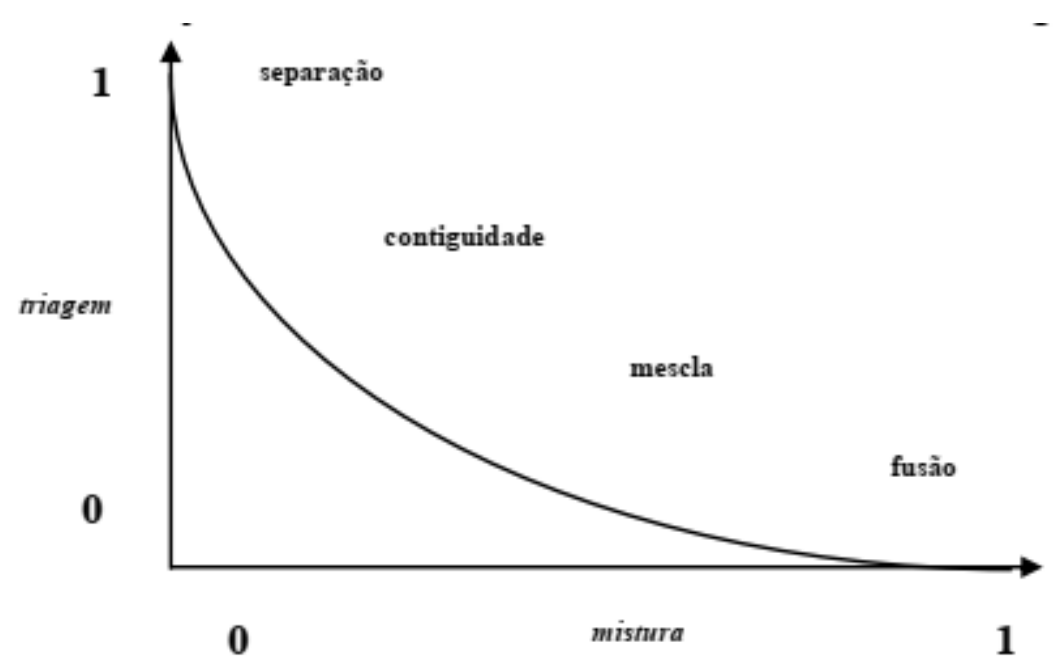

Fonte: Zilberberg (2004, p. 77)

Para tratar da junção no intervalo canônico, entre aquilo que é átono e tônico, Zilberberg (2000) aponta para momentos aspectuais, levando em consideração a direção e a intimidade entre dois corpos miscíveis, sendo eles: a separação, a contiguidade, a mescla e a fusão. Segundo o autor, na separação, a valência da triagem ocorre de forma plena enquanto a mistura seria nula. No que concerne à fusão, nos deparamos com a situação inversa das valências, isto é, mistura plena e triagem nula. Na contiguidade, nota-se que a triagem sobressai à mistura e na mescla, "[...] a triagem passa de dominante a dominada" (ZILBERBERG, 2000, p. 12, tradução nossa) ${ }^{7}$. Abaixo, reproduzimos a representação desses estados aspectuais:

7 No original: "[...] le tri passe de dominant à dominé". 
Figura 1. Os quatro estados aspectuais da mestiçagem

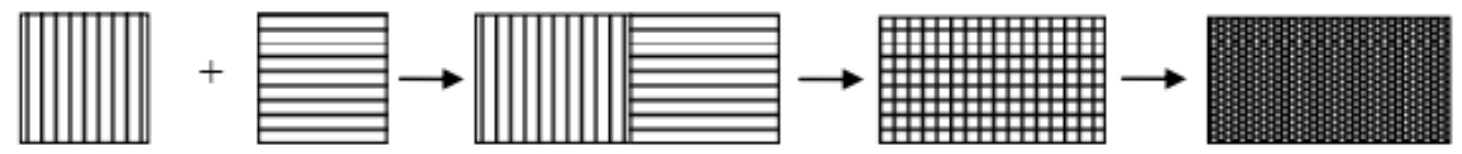

Fonte: Zilberberg (2004, p. 76)

Como esclarece Moreira (2019), o estudo zilberberguiano sobre a mestiçagem é relevante para a compreensão do papel da citação nos discursos científicos, haja vista possibilitar a identificação, de um ponto de vista semiótico, de uma tipologia de citação ${ }^{8}$ em trabalhos acadêmicos: a citação direta, que pode ser curta (até três linhas) e longa (mais de três linhas); a citação indireta (paráfrase) - esses dois tipos de citações, reconhecidos pelas normas de citação em trabalhos acadêmicos, como ABNT, APA, Vancouver, etc. - e a citação que nomeamos "assimilada".

\section{Intensidade de referenciação do discurso: os tipos de citações}

Constitutivo de todo discurso científıco, o recurso de utilizar citações para ratificar a argumentação pode ser entendido como uma recuperação anafórica do discurso de outrem, ou seja, como um discurso referencial, conforme Greimas (1981 [1976]). Nesse sentido, a citação direta, curta ou longa, ocorre por meio da intertextualidade, ao passo que a interdiscursividade rege a formação da citação indireta, dois procedimentos (da intertextualidade e da interdiscursividade) já incorporados à metalinguagem da Semiótica Discursiva (BARROS, 2009).

No âmbito de uma investigação historiográfica, no entanto, as citações diretas e indiretas não são os únicos tipos de discurso referencial a serem considerados pelo pesquisadorautor. Cada vez que o trabalho de um autor é atualizado em um discurso outro e realizado ao se transformar em citação (discurso referencial, em termos semióticos, ou argumento de influência, de uma perspectiva historiográfica), carrega consigo um clima de opinião específico. Desse modo, a periodicidade ou o momento histórico de construção teórica em que as contribuições de um pesquisador são chamadas a compor um discurso referencial pode ser um indicativo de sua relevância para um dado campo teórico.

Na perspectiva de Koerner (2014), quando um historiógrafo investiga o reconhecimento público de uma obra, uma das formas, a priori, de verificar a aceitabilidade ou a recusa de um discurso científico, é a observância da escolha desta ou de outra contribuição para compor o discurso referencial de um trabalho. Para vermos como isso acontece,

8 Aqui, está incluída a citação de citação, pois, referenciada como tal, por intermédio do uso do apud, a sua ocupação textual pode ser direta (longa e curta) ou indireta. 
observemos, no artigo "Semiótica plástica e linguagem publicitária" (1987 [1981]), de Jean-Marie Floch, como o discurso em que um trabalho-citante, que chamaremos de $\mathrm{C1}$, ao citar um trabalho, que nomeamos $\mathrm{T} 1$, enuncia um discurso referencial, isto é, utiliza o recurso de anaforização intertextual - citação direta (curta ou longa) - e/ou interdiscursiva - citação indireta:

1. "O propósito do estudo [...] implica abordagem metodologicamente bem distinta daquela praticada principalmente por R. Barthes em seu artigo de 1964, 'Retórica da imagem' (a respeito das 'Massas Panzani' em Communications, $\left.n^{\circ} 4\right)^{\prime}$. [T1]

2. "A publicidade seria o refúgio da poesia? Para justificar a incongruência de tal questão, notar-se-á que [...] o anúncio joga [...] com a colocação do enunciado em sistema: Roman Jakobson diria com a 'projeção do eixo paradigmático sobre o eixo sintagmático"' [T1].

No primeiro exemplo, a citação indireta do trabalho de Barthes por Floch tem função negativa, uma vez que $\mathrm{T} 1$ é citado para ser, em seguida, refutado pelo semioticista do Groupe de Recherches Sémio-linguistiques (GRSL). No segundo exemplo, fazendo uso de citação direta curta, Floch cita Jakobson para embasar o seu argumento, dessa maneira, aprovando o trabalho do linguista russo. Todavia, tanto na citação indireta quanto na citação direta curta, representada pelas aspas simples, a citação pode ser representada da seguinte maneira:

Figura 2. Sintagma simples de citação direta e indireta de proposições teóricas

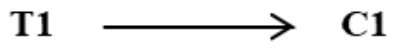

Fonte: Adaptado de Santos (2020, p. 94)

Há, contudo, outro caso de anaforização interdiscursiva, nesse caso, mais complexo do que a citação indireta ora apresentada. Ao contrário da citação de citação em que o uso do "apud" informa ao enunciatário-leitor que a citação não pertence, de fato, a dado autor e dada obra, mas a outro autor, anterior ao imediatamente citado, existem citações indiretas que citam o trabalho de um pesquisador sem mencioná-lo, fazendo referência a outro. Em outras palavras, a proposta de T1 não é imediatamente atribuída a ele pelo $\mathrm{C} 1$. O leitor (re)conhece o T1 no discurso do C1, porém por intermédio da citação de C1 por C2, como vemos na citação feita por Eduardo Peñuela Canizal (1987, p. 4, grifos nossos), na apresentação do número 6 da revista Significação, de um artigo de Ignacio Assis Silva (1987): 
3. "[...] Ignacio Assis Silva [1987a], ao assinalar a transformação da função prática em função mítica, confere aos chamados semas contextuais a condição de domínio por excelência da atividade humana [...]". [C2]

Contudo, no texto citado, Silva (1987, p. 53, grifos nossos) [C1] afirma que

Para Greimas (1966: 65) [T1], as figuras sêmicas, que constituem o que estamos chamando de base sêmica, situam-se no interior do processo de percepção [...] A essa luz, o conjunto formado pelos semas contextuais assume a característica de lugar ou instância de mediação entre o âmbito daquilo que é representado pela base sêmica [...] e [...] pela base classemática.

Nota-se, comparando as citações, que na recuperação anafórica de Silva (1987), indiretamente, Cañizal (1987) retoma Greimas (1966), que observou, antes do pesquisador brasileiro, que os semas contextuais possibilitam o reconhecimento do mundo natural pelas línguas naturais. Em suma, T1 (Greimas) é citado por C2 (Cañizal) por intermédio de C1 (Silva), ficando, o movimento de citação, assim representado:

Figura 3. Sintagma composto de citação indireta de proposições teóricas

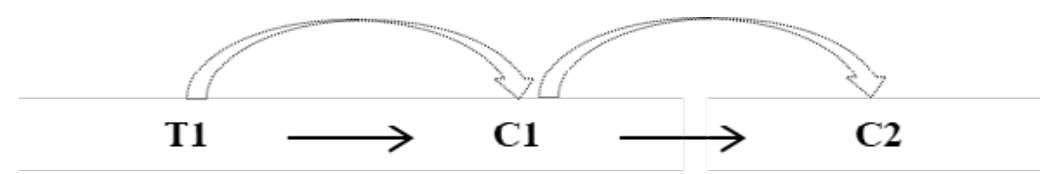

Fonte: Adaptado de Santos (2020, p. 95)

Esse tipo de citação, de acordo com Romancini (2010, p. 20), apresenta, portanto, um caráter recursivo na medida em que "[...] um texto pode citar outro que se refira a outros textos etc. [...]", formando, dessa maneira, uma rede citacional.

Um tipo de citação que dificulta ainda mais chegar ao reconhecimento público é aquela em que o enunciador se apropria de uma proposição teórica "[...] como se fosse senso comum no campo ou na disciplina [...]", não Ihe ocorrendo citar uma fonte primeira daquela ideia (SANTOS, 2020, p. 95). Visto que, segundo Batista (2013), o clima de opinião também pode ser considerado argumento de influência, acreditamos que, em termos landowskianos, é como se, nesse caso, todos os enunciatários tivessem sido contaminados por um mesmo modo de pensar, não sendo possível distinguir quem contaminou e quem foi contaminado (LANDOWSKI, 2005) - perspectiva que pode ser pensada historiograficamente em quem influenciou e quem foi influenciado -, pelo outro na interação entre pesquisadores-autores dentro de um mesmo campo de pesquisa. Em outras palavras, na ocasião da construção conjunta de contribuições teóricas - processo que implica muitos debates teóricos, não estando, portanto, definido a quem pertencem 
tais e tais conceitos e definições - pode ser difícil atribuir crédito a um ou a outro enunciador quando há publicação, muitas vezes, simultânea de mais de um trabalho em torno de uma mesma problemática, como vemos nos exemplos abaixo:

4. "[...] na pintura 'poética', as figuras [...] encontram-se rearticuladas graças a um código semissimbólico, que consiste em colocar em relação categorias semânticas [conteúdo] e categorias plásticas [expressão] (topológicas, eidéticas e cromáticas)". (THÜRLEMANN, 1981, p. 46, grifos nossos).

5. "Aceitando-se reservar o nome de semióticas semissimbólicas para esse tipo de organização de significação - que se definem pela conformidade entre os dois planos de linguagem reconhecida como se dando não entre elementos isolados, como acontece nas semióticas simbólicas, mas entre suas categorias [...]". (GREIMAS, 1984, p. 41-42, grifos nossos).

6. "[...] as linguagens semissimbólicas caracterizam-se não pela conformidade de elementos da expressão e do conteúdo isolados, mas pela conformidade de certas categorias desses dois planos". (FLOCH, 1987 [1981], p. 43, grifos nossos).

7. "Os sistemas semissimbólicos distinguem-se dos sistemas simbólicos [...]: as relações são estabelecidas entre categorias e não entre termos isolados da expressão e do conteúdo". (BARROS, 1987, p. 6, grifos nossos)

Nos exemplos (4), (5), (6) e (7), fica claro que, nos anos 1980, o clima de opinião em torno do entendimento sobre o semissimbolismo ${ }^{9}$ faz com que esse conceito semiótico seja entendido da mesma forma por semioticistas europeus e brasileiros, sem que deem crédito a um ou outro pela definição, muitas vezes, utilizando o mesmo conjunto de léxicos, outras vezes, empregando lexemas sinônimos. Assim, "código semissimbólico", "semióticas semissimbólicas", "linguagens semissimbólicas" e "sistemas semissimbólicos", segundo Thürlemann (1981), Greimas (1984), Floch (1987 [1981]) e Barros (1987), respectivamente, são expressões que se voltam para a homologação da conformidade entre categorias dos planos da linguagem (também conhecidos como conteúdo e expressão ou categorias semânticas e categorias plásticas).

Esses quatro últimos exemplos revelam, por fim, que, dessa interação complexa de proposições teóricas, surge um tipo de discurso referencial de intensidade mínima de reconhecimento público, chamado por Moreira (2019, p. 57) de "citação assimilada"; um

9 O conceito de "semissimbólico", formulado por Thürlemann e Floch, entra para o Tomo II do Dicionário de Semiótica, organizado por Greimas e Courtés, em 1986. 
tipo de citação que, fundida ao discurso do enunciado enunciado citante, se configura como a extensão máxima da mistura dos enunciados do texto-citante e do texto-citado. Instalada no âmbito do enunciado enunciado, a citação assimilada revela, no extremo da grandeza de intensidade, uma intensidade tônica da atividade interpretativa, pois exige maior investimento dessa atividade por parte do enunciatário-leitor. Trata-se de um discurso manifestado do qual é impossível, para um leitor com pouca bagagem teórica, sobretudo, recuperar o reconhecimento público sem "[...] uma prova textual que confırme a real influência. Essa operação pode ocorrer de forma consciente ou não, já que fatores extralinguísticos [...] podem interferir [...]" no discurso manifestado pelo texto-citante (MOREIRA, 2019, p. 57). A ilustração a seguir mostra como se dá essa relação em que não existe texto-citante e texto-citado, mas sim dois ou mais trabalhos $(\mathrm{T} 1, \mathrm{~T} 2, \mathrm{~T} 3, \mathrm{TN}+1$...) que se misturam:

Figura 4. Sintagma de citação assimilada

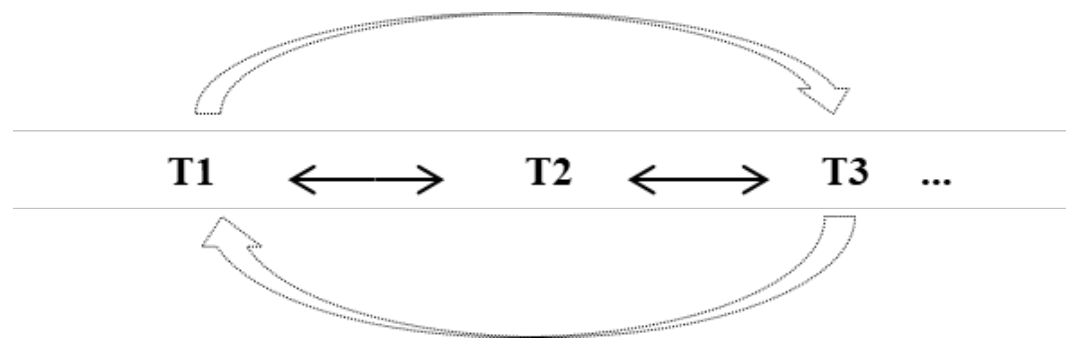

Fonte: Elaboração própria

Essa fusão de um discurso ao outro, que conforma a citação assimilada, pode ser explicada pelos regimes tensivos da triagem e da mistura (mestiçagem).

\section{Entre triagens e misturas: os graus de incorporações discursivas das citaçôes}

Semioticamente, a construção do discurso referencial por meio de citações pode ser entendida de uma perspectiva tensiva, aquela das triagens e das misturas. Do ponto de vista da mistura, Zilberberg acrescenta ao modelo canônico a problemática da mestiçagem, que é compreendida como uma variedade da mistura, cuja tipologia vai ao encontro de nossa abordagem em relação às citações. A mestiçagem ocupa uma região específica no espaço tensivo (ZILBERBERG, 2000), relacionando-se duplamente com a triagem e a mistura.

Transpondo as ideias zilberberguianas sobre a mestiçagem na tipologia citacional, percebemos, na citação direta longa, que, no regime da triagem, enquanto temos uma intensidade quase nula da atividade interpretativa do enunciatário (inexistência de visada perceptiva para discriminar a citação), também temos uma intensidade tônica de referenciação, que demanda um recuo textual no texto-citante referente ao texto- 
citado, separando por completo o enunciado citado daquele que o cita. No estado aspectual da separação, ela fica, portanto, disjunta do texto que a engloba. A citação direta curta, normalmente marcada pelo uso de aspas duplas, amalgama-se à totalidade do texto-citante, tornando-se mais próxima de ser parte dele do que de não ser. Mais próxima da triagem, porém já em processo de mistura, por seu caráter incoativo, nesse sentido, à citação direta curta corresponde o estado da contiguidade. Com base na identificação desses estados aspectuais, seja na citação direta longa, seja na curta, há um reconhecimento público explícito do discurso referencial, uma vez que são disponibilizados, ao enunciatário, dados como: autor, ano e página do texto citado. Não bastasse o fato de a citação direta reproduzir ipsis litteris a obra original, a separação total aumenta a importância do enunciado-outro para o texto-citante, produzindo um valor "mais" veridictório e transparecendo seu sentido e sua fonte de influência, mesmo que a função no texto seja superficial, comparada ou negada, em termos smallianos, como mostramos no exemplo (2).

Conjunta do texto-citante, a citação indireta é constituída de um discurso do textocitado ( $\mathrm{T} 1$ ) muito mais arraigado ao discurso do texto-citante (mescla), conforme exemplo (1). Em razão de seu aspecto progressivo, a citação indireta, complexa ou simples, identifica-se, entre os graus de mestiçarem, à mescla. Esse estado aspectual ainda permite a identificação do reconhecimento público, uma vez que as paráfrases também são acompanhadas de informações como autoria, datação e paginação. No caso exemplificado, Floch (1987 [1981]) informa até mesmo onde o artigo de Barthes fora publicado. O reconhecimento público somente é, de fato, severamente prejudicado na citação assimilada, haja vista a ausência total de referência ao texto-citado, ficando, o discurso de T1, completamente incorporado ao discurso enunciado pelo texto-citante. De aspecto terminativo, caracterizado não somente pela conjunção completa, mas também pelo predomínio da inerência (estado inseparável de dois ou mais discursos), nesse caso, ocorre o ápice da mistura, no qual mais do que uma mescla entre discursos/textos, emerge uma fusão entre eles (ZILBERBERG, 2000). Assim, a distribuição das citações pode ser resumida nos gráficos a seguir:

Gráficos 2 e 3. Tipologia das citações tensivas da perspectiva da referenciação e da atividade interpretativa
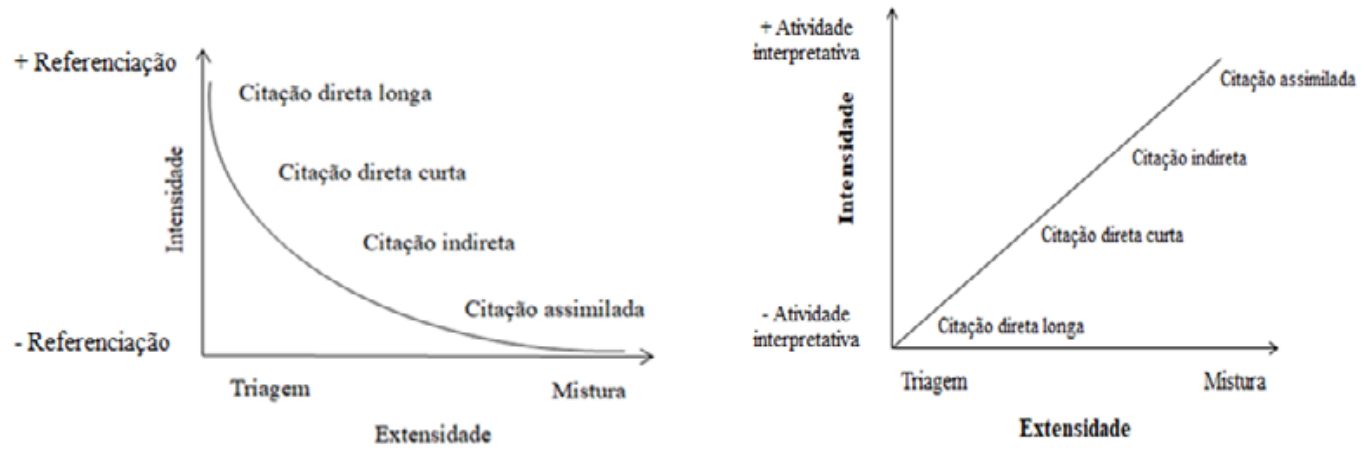

Fonte: Adaptado de Moreira (2019, p. 56-57) 
No regime da mistura, os gráficos nos mostram como os enunciados se mesclam (formação de paráfrases na citação indireta) ou se encontram em estado de fusão (citação assimilada). A recuperação do reconhecimento público pelo historiógrafo exige um estudo mais aprofundado no sentido de levantar evidências das fontes utilizadas pelos citantes. Além disso, a disponibilização da fonte completa, no caso da citação direta e da citação indireta, facilita a recuperação da influência, ao passo que a presença do nome do autor e do ano da obra, apenas, sem paginação, dificulta a identificação do discurso referencial (texto-citado ou original), impondo ao enunciatário a busca, por conta própria, do enunciado referenciado, isto é, exige uma visada mais intensa para a recuperação da parte não mencionada da citação (ano e/ou página) em termos de atividade interpretativa. Situação semelhante ocorre no exemplo (2) (citação direta curta), em que há referência ao autor (Jakobson) do texto citado, este último indicado por aspas, mas não são informados o ano nem a obra em que a citação foi publicada.

Pensando, portanto, na intensidade de referenciação e nos graus de incorporações das citações nos textos como procedimentos semio-historiográficos na busca assertiva de influências reivindicadas de um autor sobre o outro, entendemos que o reconhecimento público diz respeito ao modo de construção do discurso científico que coloca também em circulação questões sobre autoria (identidade vs. alteridade, objetividade vs. subjetividade), efeitos de veridiç̧ão, entre outros elementos essenciais na compreensão histórica do saber cumulativo nas ciências (memória vs. esquecimento).

Observando essas duas questões em mais um exemplo (8), buscamos uma rede citacional em Landowski, que, ao retratar a condição do homem como condenado ao sentido, retoma Merleau-Ponty, citado indiretamente por Barthes, cujas obras aparecem em nota de rodapé (LANDOWSKI, 2006). No mesmo exemplo, Greimas aparece sem referência, o que cria um movimento de citação indireta composta: T1 (Merleau-Ponty) é citado por C2 (Barthes/Greimas) por intermédio de C1 (Landowski):

8. "[...] para caracterizar nossa condição, ou ao menos aquela do 'escritor', Barthes tinha tomado emprestado de Merleau-Ponty uma fórmula bastante estranha que Greimas também amava repetir, generalizando-a: seres semióticos por natureza, nós seríamos por natureza 'condenados ao sentido"' (LANDOWSKI, 2006, p. 10, grifos nossos, tradução nossa) $)^{10}$.

Concernente à referência a Greimas no exemplo acima, é clara, nesse texto landowskiano, a alusão a Da imperfeição (1987), contudo, notamos no texto do mestre lituano a sua preocupação com a condenação dos seres semióticos ao sentido ainda em Semântica Estrutural (1966):

10 No original: "Pour caractériser notre condition, ou du moins celle de l'écrivain', Barthes avait emprunté à Merleau-Ponty une formule assez étrange que Greimas aimait aussi à répéter, en généralisant : êtres sémiotiques par nature, nous sérions par nature 'condamnés au sens"'. 
9. 'Nós ficamos ingenuamente surpresos quando refletimos sobre a situação do homem, que de manhã à noite e da idade pré-natal à morte, é literalmente atacado pelas significações que o solicitam por todos os lugares, por mensagens que lhe alcançam a todo o momento e sob todas as formas" (GREIMAS, 1966, p. 8, grifos nossos, tradução nossa) ${ }^{11}$.

Não podemos afirmar absolutamente que Landowski desconhecia esse trecho de Semântica estrutural, sendo ele um semioticista e conhecedor profundo da obra de Greimas. Logo, além das provas textuais, cabe ao semioticista-historiógrafo levar em consideração o clima de opinião e o background do autor antes de assumir um posicionamento mais acabado em relação à presença ou ausência de uma citação indireta ou assimilada (KOERNER, 1987; BATISTA, 2013; SANTOS, 2020). Desse modo, correlacionando os exemplos (8) e (9), é possível dizer que no exemplo (9) também estamos diante de uma citação parcialmente assimilada, cuja prova textual poderia ser recuperada por um leitor mais atento da obra de Landowski (2006) ou ainda conhecedor da fenomenologia de Merleau-Ponty (1945), conforme exemplo (10):

10. [...] porque nós estamos no mundo, nós estamos condenados ao sentido e, nós não podemos fazer nada, nem dizer nada que não tome um nome na história. (MERLEAUPONTY, 2011 [1945], p. 26, grifos nossos, tradução nossa) ${ }^{12}$.

Temos, nesse caso, a fusão completa, se o leitor desconhecer o texto merleau-pontyano, ou, de forma mais exemplar e, indiscutivelmente, nos exemplos (4), (5), (6) e (7). Ou, ainda, a ausência, no texto-citante, do texto-citado, colocando em relação, consequentemente, dois trabalhos (T1 - Merleau-Ponty) e (C1 - Greimas), já que Greimas não menciona Merleau-Ponty no excerto (9). Esses textos (citante-citado) se misturam e demonstram, ao mesmo tempo, o clima de opinião vigente durante a publicação de Semântica estrutural, cujo estruturalismo europeu recebeu fortes influências das mais variadas fenomenologias (DOSSE, 2007).

\section{Algumas considerações}

Ao longo deste trabalho, procuramos, por meio das metalinguagens historiográfica e semiótica, sincretizadas em uma semio-historiografia, estabelecer o reconhecimento público como principal parâmetro no argumento de influência de determinado autor e/ ou obra sobre outro na Semiótica Discursiva. Tratando-se de um aspecto voltado para a

11 No original: "On est naïvement étonné quand on se met à réfléchir sur la situation de l'homme qui, du matin au soir et de l'âge prénatal à la mort, est littéralement assailli par les significations qui le sollicitent partout, par les messages qui l'atteignent à tout instant et sous toutes les formes".

12 No original: "[...] parce que nous sommes au monde, nous sommes condamnés au sens, et nous ne pouvons rien faire ni rien dire qui ne prenne un nom dans l'histoire". 
imanência do texto, isto é, da análise de elementos encontrados no enunciado enunciado e na enunciação enunciada, buscamos arrolar alguns procedimentos semióticos para compreender a citação em textos científicos, tomados como objetos de possíveis historiografias linguísticas, enquanto construção coletiva de "realizações científicas" (LEYSDESDORFF, 1998) próprias a um determinado momento e grupo de cientistas, neste caso, no campo da semiótica discursiva.

Para tanto, apoiamo-nos, sobretudo nos procedimentos semióticos de intertextualidade, interdiscursividade e mestiçagem como constituintes do reconhecimento público historiográfico. Destacamos alguns elementos decorrentes deste trabalho: i) a reflexão sobre as citações pode contribuir para o argumento de influência, caro à $H L$, na medida em que as citações direta e indireta constituem prova textual necessária ao reconhecimento público. Embora a citação assimilada (enunciado não enunciado) impossibilite que este último ocorra de maneira explícita, o conhecimento sobre o background do autor pode ajudar a comparar e identificar os discursos que perpassam os textos-fonte analisados pelo historiógrafo; ii) Há uma gradação da marcação textual que acompanha a referência direta ao discurso de outrem até chegar à citação assimilada, totalmente misturada, de modo que não tem como o enunciatário saber ao certo onde começa e onde termina o discurso do enunciador e o discurso referencial.

Evidentemente, os questionamentos iniciais não foram completamente esgotados, mas pudemos demonstrar, com exemplos diversos, como essa questão pode ser conduzida pelos pesquisadores interessados em estudar as influências de um determinado monumento (no sentido historiográfico), autor, obra, conceito, de maneira consciente, utilizando diferentes ferramentas, como a correlação que fizemos entre os tipos de citação (simples, complexa, assimilada) e os efeitos de veridicção, identidade, objetividade e mestiçagem, por triagem ou mistura. Dito isso, concluímos que as citações analisadas pela abordagem da $\mathrm{HL}$, grosso modo, reparam e restauram ao mesmo tempo o esquecimento das ideias linguísticas. Segundo Colombat et al. (2015, p. 12), os saberes são construídos na longa duração do tempo, uma vez que a acumulação de conhecimentos coloca em circulação nos textos tanto a memória quanto o esquecimento. Assim, o historiador "[...] produz a informação sobre o sistema científico que as ciências da linguagem constituem e permite, portanto, expandir, para os pesquisadores, aquilo que podemos chamar de 'horizonte de retrospecção'[...]" (COLOMBAT et al., 2015, p. 13, tradução nossa) $)^{13}$, objetivando recuperar a própria construção do saber científico como uma rede referencial.

13 No original: "[...] produit de l'information sur le système scientifique que constituent les sciences du langage et permet donc d'élargir, chez les chercheurs, ce que l'on peut appeler leur 'horizon de rétrospection' [...]". 


\section{Agradecimentos}

Agradecemos ao CNPq (processo n. 312227/2017-5), à FAPESP (processo n. 16/224660) e à Coordenação de Aperfeiçoamento de Pessoal de Nível Superior - Brasil (CAPES) - Código de Financiamento 001, pelo financiamento recebido para a realização deste trabalho.

\section{REFERÊNCIAS}

AKSNES, D. W.; LANGFELDT, L.; WOUTERS, P. Citations, Citation Indicators, and Research Quality: An Overview of Basic Concepts and Theories. SAGE Open. 2019. Disponível em: https://doi.org/10.1177/2158244019829575. Acesso em: 30 abr. 2019.

ALTMAN, C. Retrospectivas e perspectivas da historiografia da linguística no Brasil. Revista Argentina de historiografia linguística, n. 1, p. 115-136, 2009. Disponível em: http://www.rahl.com.ar/index.php/rahl/article/view/12. Acesso em: 20 mar. 2018.

AUROUX, S. A questão da origem das línguas, seguido de A Historicidade das Ciências. Tradução Mariângela Pecciolli Gali Joanilho. Campinas: Editora RG, 2008.

BARROS, D. L. P. de. Problemas de expressão: figuras de conteúdo e figuras de expressão. Significação - Revista Brasileira de Semiótica, São Paulo, n. 6, p. 5-12, 1987.

BARROS, D. L. P. de. Uma reflexão semiótica sobre a "exterioridade" discursiva. Alfa Revista de Linguística, Universidade Estadual Paulista "Júlio de Mesquita Filho", v. 53, n. 2, p. 351-364, 2009. Disponível em: http://seer.fclar.unesp.br/alfa/article/view/2120/1738. Acesso em: 14 abr. 2017.

BATISTA, R. O. Introdução à historiografia da linguística. São Paulo: Cortez, 2013.

CAÑIZAL, E. P. Apresentação. Significação - Revista Brasileira de Semiótica, Ribeirão Preto, n. 6, p. 3-4, 1987.

COLOMBAT, B.; FOURNIER, J.-M.; PUECH, C. Histoire des idées sur le langage et les langues. Paris: Klincksieck, 2015.

DOSSE, F. História do estruturalismo. v. I. Tradução Álvaro Cabral. Bauru: EDUSC, 2007.

FLOCH, J.-M. Semiótica plástica e linguagem publicitária. Significação - Revista Brasileira de Semiótica, São Paulo: Gráfica da Escola de Com. e Artes - USP, n. 6, p. 29-50, 1987. 
GREIMAS, A. J. Semiótica Figurativa e Semiótica Plástica. Significação - Revista Brasileira de Semiótica, Araraquara, n. 4, p. 18-46, 1984.

GREIMAS, A. J. Sémantique Structurale. Paris: Larousse, 1966.

GREIMAS, A. J.; COURTÉS, J. Dicionário de semiótica. Tradução Diana Luz Pessoa de Barros et al. São Paulo: Contexto, 2008.

GREIMAS, A. J.; COURTÉS, J. Sémiotique: dictionnaire raisonné de la théorie du language. Tome II. Paris: Hachette, 1986.

KOERNER, E. F. K. O problema da "influência" na historiografia linguística. In: KOERNER, E. F. K. Quatro décadas de historiografia linguística: estudos selecionados. Vila Real: Universidade de Trás-os-Montes e Alto Douro, Centro de Estudos em Letras, Coleção Linguística 11, prefácio de Carlos Assunção, seleção e edição de textos de Rolf Kemmler e Cristina Altman, 2014. p. 91-102.

KOERNER, E. F. K. Questões que persistem em historiografia lingüística. Revista da ANPOLL, São Paulo, v. 1, n. 2, p. 45-70, 1996. Disponível em: https://revistadaanpoll.emnuvens.com. br/revista/article/view/240/253. Acesso em: 21 mai. 2016.

KUHN, T. S. A estrutura das revoluções científicas. Tradução Beatriz Vianna Boeira e Nelson Boeira. São Paulo: Perspectiva, 1997.

LANDOWSKI, E. Aquém ou além das estratégias, a presença contagiosa. Documentos de Estudo do Centro de Pesquisas Sociossemióticas. São Paulo: Edições CPS, 2005.

LANDOWSKI, E. Les interactions risquées. Les Noveaux Actes Sémiotiques, Limoges, n. 101, 102, 103, p. 7-106, 2006.

LEYDESDORFF, L. Theories of Citation? Scientometrics. v. 43, n. 1, 1998 [não paginado]. Disponível em: https://www.leydesdorff.net/citation/. Acesso em: 20 fev. 2019.

LIMA, E. S. de. De triagens a misturas: por uma compreensão semiótica do processo de transposição didática. Estudos Semióticos [on-line], São Paulo, v. 15, n. 2, p. 114-132, 2019. Disponível em: http://www.revistas.usp.br/esse/article/view/165206/158320. Acesso em: 20 set. 2020.

MERLEAU-PONTY, M. Phénomenologie de la perception. Paris: Gallimard, 2011. 
MOREIRA, P. V. A emergência do sensível na semiótica discursiva: uma abordagem historiográfica. 2019. Tese (Doutorado em Linguística e Língua Portuguesa) - Faculdade de Ciências e Letras, Universidade Estadual Paulista "Júlio de Mesquita Filho", Araraquara. 2019 .

PORTELA, J. C. História das ideias semióticas: entre cronistas e inovadores. Estudos Semióticos, São Paulo, v. 14, n. 1 (edição especial), mar. 2018.

ROMANCINI, R. O que é uma citação? A análise de citações na ciência. Intexto, Porto Alegre: UFRGS, v. 2, n. 23, p. 20-35, jul./dez. 2010. Disponível em: https://seer.ufrgs.br/ intexto/article/view/15885/10508. Acesso em: 12 mar. 2019.

SANTOS, F. K. R. O conceito de figuratividade e as práticas de institucionalização da semiótica no Brasil e na França. 2020. Tese (Doutorado em Linguística e Língua Portuguesa) Faculdade de Ciências e Letras, Universidade Estadual Paulista "Júlio de Mesquita Filho", Araraquara. 2020.

SILVA, I. A. A construção do ator: do sígnico ao simbólico. Significação - Revista Brasileira de Semiótica, São Paulo, n. 6, v. 1, p. 51-57, 1987.

THÜLERMANN, F. La double spatialité en peinture: espace simulé et topologie planaire. Actes Sémiotiques: Bulletin, Paris: EHESS-CNRS, n. 20, p. 34-46, 1981.

ZILBERBERG, C. As condições semióticas da mestiçagem. Tradução Ivã Carlos Lopes e Luiz Tatit. In: CAÑIZAL, E. P.; CAETANO, K. E. (org.). O olhar à deriva: mídia, significação e cultura. São Paulo: Annablume, 2004. p. 69-101.

ZILBERBERG, C.; FONTANILLE, J. Tensão e Significação. Tradução Ivã Carlos Lopes et al. São Paulo: Discurso Editorial: Humanitas/FFLCH/USP, 2001.

ZILBERBERG, C. Les contraintes sémiotiques du métissage. Tangence, n. 64, p. 8-24, 2000. 